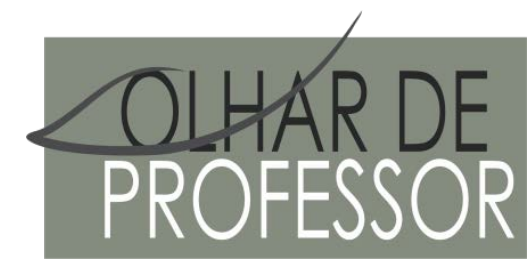

DOI: 10.5212/OLHARPROFR.V.2111.0009

\title{
UM PANORAMA DO ENSINO DE CIÊNCIAS DO MUNICÍPIO DE CAMBUCI/RJ: 0 QUE TEM SIDO FEITO E A NECESSIDADE DE MUDANÇAS
}

\section{AN OVERVIEW OF SCIENCE TEACHING IN THE MUNICIPALITY OF CAMBUCI/RJ: WHAT HAS BEEN DONE AND THE NEED FOR CHANGES \\ UN PANORAMA DE LA ENSEÑANZA DE LAS CIENCIAS DEL MUNICIPIO DE CAMBUCI / RJ: LO QUE SE HA HECHO Y LA NECESIDAD DE CÂMBIOS}

CASSIANA BARRETO HYGINO MACHADO*
FRANCILAYNE OLIVEIRA
ISABELLY CARVALHO
TORQUATO PINHEIRO
T*k*
BRUNO FERNANDES

Resumo: Nesta pesquisa realizou-se um levantamento sobre o ensino de ciências no município de Cambuci/RJ, a fim de identificar como é o ensino atual praticado nas escolas e quais suas necessidades. Para isso responderam a um questionário 33 professores atuantes no primeiro segmento do ensino fundamental, professores de ciências do segundo segmento do ensino fundamental e professores de física, química e biologia do ensino médio de 8 escolas públicas do município. A partir da análise identificou-se que poucos professores possuem formação na área de ciências naturais. As escolas possuem poucos espaços destinados ao ensino de ciências, entretanto os professores buscam formas alternativas para o seu ensino, como feira de ciências. As práticas dos professores têm como modelos didáticos predominantes: tradicional, tecnológico e em alguns casos espontaneista. Evidenciou-se a necessidade de vincular o ensino de ciências as questões que relacionem ciência, tecnologia, sociedade e ambiente, propiciando a formação crítica dos estudantes.

Palavras-chave: Ensino de ciências. Modelos didáticos. Prática dos professores.

\footnotetext{
* Doutora em Ciências Naturais pela UENF. Professora do Instituto Federal de Educação, Ciência e Tecnologia Fluminense, IFF. Professora do Mestrado Nacional Profissional em Ensino de Física, MNPEF. E-mail: cassiana.h.machado@iff.edu.br

** Bolsista do Programa Jovens Talentos para a Ciência. Estudante do ensino médio integrado ao técnico de agropecuária, IFF. E-mail: francilayne-fonseca@hotmail.com

*** Bolsista do Programa Jovens Talentos para a Ciência. Estudante do ensino médio integrado ao técnico de agroecologia, IFF. E-mail: isabelly_scarvalho@yahoo.com.br

**** Mestre em Ciências Naturais pela UENF. Professor do Instituto Federal de Educação, Ciência e Tecnologia Fluminense, IFF. E-mail: torquato.pinheiro@iff.edu.br

${ }^{* * * * *}$ Mestre em Saúde pela UFJF. Professor do Instituto Federal de Educação, Ciência e Tecnologia Fluminense, IFF. E-mail: bruno.fernandes@iff.edu.br
} 
Abstract: In this research, a survey was carried out on the teaching of sciences in the municipality of Cambuci / RJ, in order to identify how current teaching is practiced in schools and what their needs are. For that, a questionnaire was answered by 33 teachers working in the first segment of elementary education, science teachers in the second segment of elementary education, and physics, chemistry and biology teachers of the high school of 8 public schools in the municipality. From the analysis it was identified that few teachers have training in the area of natural sciences. Schools have few spaces for science education, however, teachers are looking for alternative ways of teaching, such as science fair. The teachers' practices have as predominant didactic models: traditional, technological and spontaneous in some cases. The need to link science education with issues relating to science, technology, society and the environment has been evidenced, thus providing critical education for students.

Key-words: teaching of science, didactic models, teachers' practice.

Resumen: En esta investigación se realizó un relevamiento sobre la enseñanza de ciencias en el municipio de Cambuci / RJ, a fin de identificar cómo es la enseñanza actual practicada en las escuelas y cuáles son sus necesidades. Para ello respondieron a un cuestionario 33 profesores actuantes en el primer segmento de la enseñanza fundamental, profesores de ciencias del segundo segmento de la enseñanza fundamental y profesores de física, química y biología de la enseñanza media de 8 escuelas públicas del municipio. A partir del análisis se identificó que pocos profesores poseen formación en el área de ciencias naturales. Las escuelas poseen pocos espacios destinados a la enseñanza de las ciencias, sin embargo los profesores buscan formas alternativas para su enseñanza, como feria de ciencias. Las prácticas de los profesores tienen como modelos didácticos predominantes: tradicional, tecnológico y en algunos casos espontaneo. Se evidenció la necesidad de vincular la enseñanza de ciencias las cuestiones que relacionen ciencia, tecnología, sociedad y ambiente, propiciando la formación crítica de los estudiantes.

Palabras clave: enseñanza de las ciencias, modelos didácticos, práctica de los professores.

\section{INTRODUÇÃO}

Em geral, o ensino de ciências tem sido marcado pela excessiva memorização, sem, no entanto, levar o aluno a refletir sobre os fenômenos de estudo. Pesquisadores como Chassot (1990), Fourez (2003) e Maldaner (2007), observam que o ensino ainda se mantém de modo tradicional em nossas escolas, o que gera insatisfação por parte dos alunos.

Ao contrário deste cenário, Sasseron (2015) afirma ser necessário que o ensino de ciências possibilite ao aluno reconhecer o quanto os estudos científicos influenciam na sociedade e refletir sobre as transformações sofridas. Ou seja, de acordo com a autora, o ensino de ciências deve implicar em não apenas reconhecer os termos e os conceitos canônicos das ciências de modo a poder aplicá-los em situações atuais, mas também construir entendimento acerca de novas formas de conceber os fenômenos naturais e os impactos que estes têm sobre nossa vida.

Dessa forma, é necessário promover a formação de cidadãos alfabetizados cientificamente, capazes de fazer uma leitura diferenciada e significativa do mundo, no que se refere a diferentes situações relacionadas à ciência, tecnologia e suas implicações na sociedade e no meio ambiente. (CHASSOT, 2000; AULER; DELIZOICOV, 2001).

Os conhecimentos científicos podem ser uma ferramenta capaz de propiciar a reflexão sobre os múltiplos aspectos da realidade, bem como estimular a capacidade investigativa do aluno, para que ele assuma a condição de agente na construção do seu próprio conhecimento. (MALAFAIA; RODRIGUES, 2008).

Contudo, mudanças profundas na educação requerem esforços de vários lados, como das políticas públicas. Entretanto, as mudanças em sala de aula também podem contribuir com a formação 
de cidadãos críticos e atuantes em sua sociedade. Em particular no ensino de ciências, desde a educação infantil este ensino exerce papel importante, pois pode contribuir para que os sujeitos tenham uma melhor compreensão do mundo e das transformações que nele ocorre diariamente, em função da ação humana. Os conhecimentos dessa área podem auxiliar no entendimento acerca dos fenômenos da natureza, bem como podem ajudar o homem a compreender e questionar os diversos modos de intervenção e utilização dos recursos naturais do seu meio, compreendendo que essas intervenções trazem sempre consequências tanto para as relações sociais quanto para o meio ambiente. (BRASIL, 1997).

No contexto da sala de aula, o professor tem papel fundamental neste cenário de mudanças, o docente é o ponto de partida na construção do conhecimento científico em uma dimensão didáticopedagógica, no sentido que é ele o responsável pela mediação do processo de aprendizagem do aluno. (DELIZOICOV; ANGOTTI; PERNAMBUCO, 2009).

O mundo mudou, e consequentemente os alunos também. O perfil do professor da atualidade requer uma identidade profissional flexível, reflexivo, capaz de leituras aprofundadas sobre o fenômeno educacional. Segundo Tardiff (2002), o professor deve ser conhecedor de sua disciplina, mas também capaz de desenvolver um saber prático baseado em pedagogia e nas ciências da educação. Ser docente implica em modelar seus conhecimentos em prol da aprendizagem de seus educandos, adaptando e repensando sempre sua prática, considerando o contexto que estão seus educandos. (POZO; CRESPO, 2009).

O professor desempenha um papel insubstituível na formação de seus alunos é ele quem transforma o aluno de simples receptor de conhecimentos em cidadão reflexivo e atuante. No que tange o ensino de ciências, é o professor capaz de modificar este cenário costumeiro desse ensino, com a adoção de práticas que motivem seus alunos para o aprendizado científico.

Diante deste cenário, esta pesquisa busca conhecer e compreender como se dá o ensino de ciências no município de Cambuci, no que se refere às práticas docentes, a estrutura e/ou falta de laboratórios, os materiais didáticos utilizados e o perfil dos professores no município de Cambuci, RJ.

Para isso, foi realizada uma pesquisa com professores do município, dos primeiro e segundo segmento do ensino fundamental e professores que atuam nas disciplinas física, química e biologia do ensino médio. No que se refere ao ensino de ciências no município de Cambuci, RJ, é importante salientar que num primeiro levantamento de informações sobre o tema, verificou-se a ausência de pesquisas sobre o tema no município, não tendo sido encontrados estudos científicos que revelassem o estado da arte do Ensino de Ciências no município.

\section{MODELOS DIDATIICOS DOS PROFESSORES}

A ideia de modelo didático tem sido utilizada como uma tentativa de representar os fazeres pedagógicos dos professores. (GARCÍA PÉREZ, 2000; PORLÁN ARIZA; RIVERO GARCÍA; MARTÍN DEL POZO, 1997, 1998). As decisões tomadas pelos professores, nem sempre conscientes, que permeiam seu fazer pedagógico estão impregnadas por suas crenças e saberes tácitos. (GILPÉREZ; CARVALHO, 1992). Esse fazer pedagógico é o que se denomina modelo didático do professor. O modelo didático é um esquema mediador entre a realidade e o pensamento do professor, uma estrutura na qual se organiza o conhecimento. (CHROBAK; BENEGAS, 2006). A ideia de modelo didático permite abordar, de forma simplificada, a complexidade da realidade escolar, ao mesmo tempo em que ajuda a propor procedimentos de intervenção e a fundamentar, portanto, linhas de investigação educativa e de formação dos professores. (GARCÍA PÉREZ, 2000).

Esta pesquisa apóia-se teoricamente nos trabalhos de Garcia e Pórlan (2000) e García Pérez (2000), para os quais os modelos didáticos correspondem à atuação dos professores frente ao processo 
de ensino aprendizagem e se representa por meio de quatro modelos didáticos: o tradicional, o tecnológico e espontaneísta; caracterizados como modelos de transição e o modelo investigativo.

O modelo tradicional focaliza o conteúdo, e se caracteriza pela ênfase na transmissão destes do professor para o aluno. Neste modelo, o contexto social e os interesses dos estudantes são desconsiderados. A metodologia para a condução das atividades se deve estritamente a uma postura ativa do professor que retém os conhecimentos e deve transmiti-los.Os alunos possuem uma postura passiva e devem absorver todo o conteúdo estudado. As atividades priorizam a memorização de informações, nomes, fórmulas. Os conhecimentos são fragmentados e não apresentam qualquer relação com a realidade dos alunos. A avaliação valoriza a memorização dos conceitos transmitidos e ocorre através de exames e provas pontuais.

O modelo tecnológico procura inovar o modelo tradicional, incorporando ao currículo da escola atividades práticas, materiais didáticos atualizados e um rigoroso detalhamento dos planejamentos de ensino. A metodologia procura obter maior eficiência do processo de ensino. A avaliação tem como objetivo quantificar a aprendizagem e verificar a eficiência desta sistemática de ensino. Neste modelo o aluno também tem uma participação passiva, devendo participar das atividades programadas.

No modelo espontâneo, a ênfase está nas ideias e interesses dos alunos. A realidade dos alunos é levada em consideração em todas as atividades, que por sua vez são flexíveis e valorizam o desenvolvimento de atitudes e autonomia dos estudantes. Os conteúdos trabalhados consideram os interesses dos alunos e a avaliação focaliza o desenvolvimento dos estudantes. O professor tem o papel de líder social e afetivo, seu trabalho ocorre essencialmente no campo da prática, levando em consideração sua experiência.

Já o modelo investigativo propõe um ensino no qual tanto alunos quanto professores exercem um papel ativo. Enfatiza-se as situações problemas que exigem dos alunos posturas investigativas, nas quais, devem elaborar hipóteses e propor soluções. As atividades são contextualizadas, com temas socialmente relevantes e com incentivo da atuação dos alunos. A avaliação tem como objetivo identificar as dificuldades dos alunos e promover reflexões sobre a evolução dos estudantes.

\section{METODOLOGIA}

Esta pesquisa teve como objetivo conhecer o cenário atual do ensino de ciências no município de Cambuci/RJ e mapear as mudanças necessárias. O município de Cambuci está localizado na região noroeste do estado do Rio de Janeiro. O município possui uma população de aproximadamente 14.827 habitantes. (IBGE, 2010).

Segundo o censo do IBGE (Instituto Brasileiro de Geografia e Estatística) de 2015 a rede educacional de Cambuci é composta por 17 estabelecimentos de ensino fundamental com 1756 alunos matriculados e 4 estabelecimentos de ensino médio com 543 alunos matriculados além de um Instituto Federal de Ensino, Ciência e Tecnologia que presta serviço de ensino médio na região.

Em 2015 os alunos dos anos iniciais da rede pública da cidade tiveram nota média de 4.9 no IDEB (Índice de Desenvolvimento da Educação Básica). Os alunos dos anos finais, essa nota foi 4.9. Na comparação com cidades do mesmo estado, a nota dos alunos dos anos iniciais colocava esta cidade na posição 58 de 92. Considerando a nota dos alunos dos anos finais, a posição passava a 4 de 92. Entretanto, as notas do IDEB incidem apenas em português e matemática, não revelando a situação do ensino de ciências dos municípios.

No que se refere às avaliações em larga escala sobre o ensino de ciências, existe o PISA (Programa Internacional de Avaliação de Estudantes). No último resultado, em 2015, o qual a ênfase se deu no ensino de ciências, os resultados mostraram que o estado do Rio de Janeiro encontra-se bastante abaixo da média nacional, revelando dessa forma, a precariedade deste ensino no país e ainda mais no estado do Rio de Janeiro. 
A pesquisa foi realizada com professores que atuam na área do ensino das ciências, sendo eles professores dos primeiro segmento do ensino fundamental, professores de ciências do segundo segmento do ensino fundamental e de física, química e biologia do ensino médio, de escolas públicas do município.

Para a realização da pesquisa fez-se uma seleção das escolas que os professores atuam. Utilizouse como critério para a escolha das escolas: (I) selecionar uma escola por distrito, sendo que o município de Cambuci/RJ possui 6 distritos; (II) e que a escola selecionada oferecesse todos os níveis de ensino, desde o primeiro segmento do ensino fundamental até o ensino médio. Entretanto, algumas escolas não ofereciam todos os níveis de ensino, sendo assim houve a necessidade, em alguns casos de selecionar duas escolas por distrito. A partir desta seleção, foram pesquisados professores de 8 escolas do município, como mostra o quadro 1:

Quadro 1: escolas selecionadas no município

\begin{tabular}{|c|c|c|}
\hline Instituição & Local & Ensino Prestado \\
\hline Escola 1 & Distrito 1 & Nono ano e Ensino Médio \\
\hline Escola 2 & Distrito 1 & Ensino Fundamental 1 e 2 \\
\hline Escola 3 & Distrito 2 & Ensino Fundamental 1 e 2/ Ensino Médio \\
\hline Escola 4 & Distrito 3 & Ensino Fundamental 1 e 2/ Ensino Médio \\
\hline Escola 5 & Distrito 4 & Ensino Fundamental 1 e 2 \\
\hline Escola 6 & Distrito 5 & Ensino Fundamental 1 \\
\hline Escola 7 & Distrito 6 & Ensino Fundamental 1 e 2 \\
\hline Escola 8 & Distrito 6 & Ensino Fundamental 1 e 2 \\
\hline
\end{tabular}

Fonte: elaboração própria

Destas escolas foram selecionados 33 professores. A fim de identificar as concepções destes professores sobre questões referentes ao ensino de Ciências, foi construído um questionário conforme apresentado na Figura 1.

O uso de questionários segundo Gil (1999, p. 128), pode ser definido "como a técnica de investigação composta por um número mais ou menos elevado de questões apresentadas por escrito às pessoas, tendo por objetivo o conhecimento de opiniões, crenças, sentimentos, interesses, expectativas, situações vivenciadas etc.” O mesmo autor supracitado apresenta as seguintes vantagens do questionário sobre as demais técnicas de coleta de dados::

a) possibilita atingir grande número de pessoas, mesmo que estejam dispersas numa área geográfica muito extensa, já que o questionário pode ser enviado pelo correio; b) implica menores gastos com pessoal, posto que o questionário não exige o treinamento dos pesquisadores; c) garante o anonimato das respostas; d) permite que as pessoas o respondam no momento em que julgarem mais conveniente; e) não expõe os pesquisadores à influência das opiniões e do aspecto pessoal do entrevistado (Gil 1999, p.128). 
Figura 1: Questionário

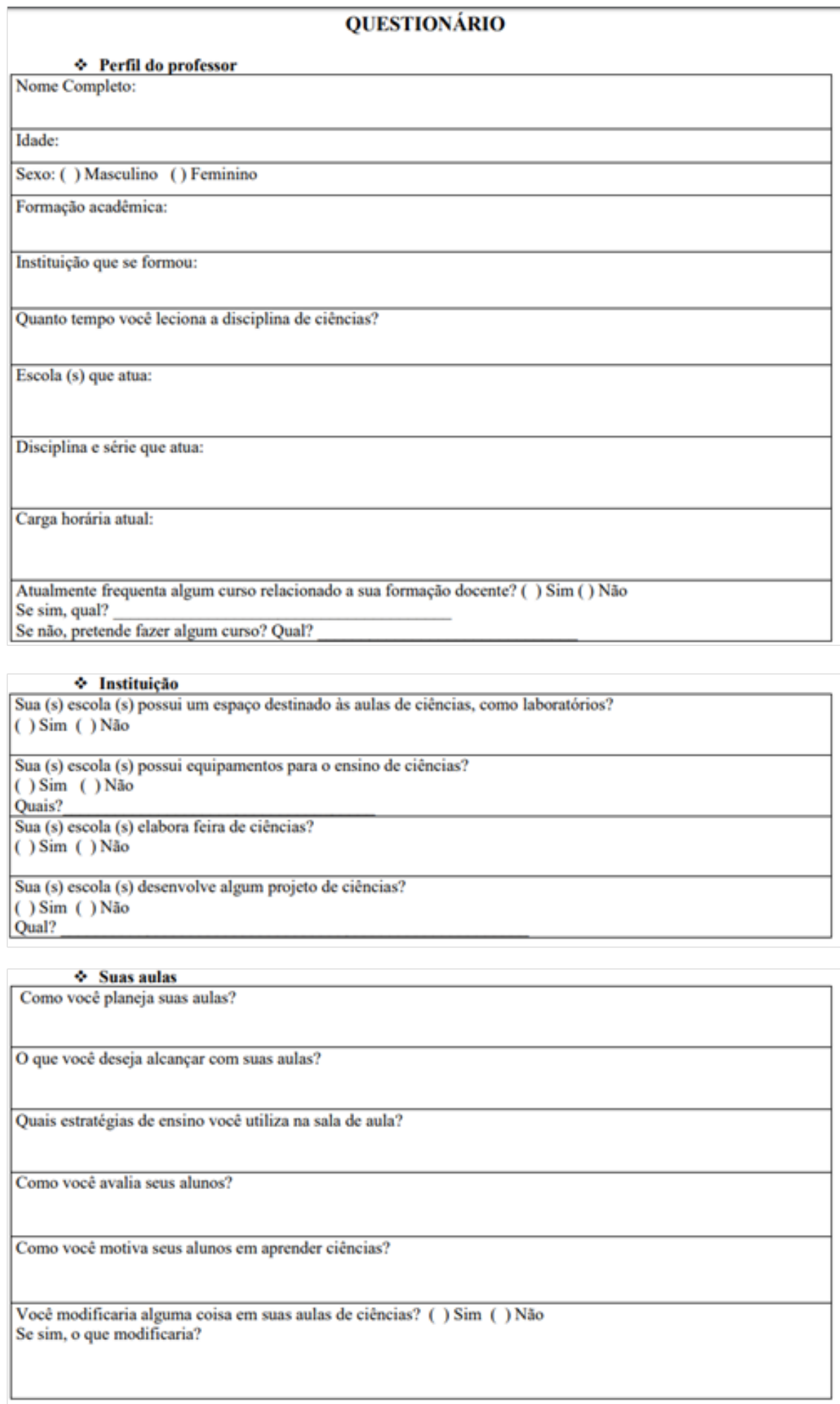

Fonte: elaboração própria

Como pode ser visto na figura 1 , o questionário continha questões abertas e fechadas que visavam reunir as informações que mostrasse como é o ensino de ciências no município de Cambuci/RJ. As perguntas nele contidas eram referentes ao perfil do professor, a estrutura da instituição que ele atua e a metodologia que ele utiliza em sala de aula. O quadro 2 apresenta o perfil do professor: 
Quadro 2: Perfil do Professor

\begin{tabular}{|c|c|c|c|}
\hline \multicolumn{2}{|c|}{ Perfil do Professor } & N & \% \\
\hline \multirow{2}{*}{ Sexo } & Masculino & 7 & 21 \\
\cline { 2 - 4 } & Feminino & 26 & 79 \\
\hline \multirow{2}{*}{ Idade } & & 23 à 59 & 55 \\
\hline \multirow{2}{*}{\begin{tabular}{c} 
Instituição em que se formou? \\
\cline { 2 - 4 }
\end{tabular}} & Pública & 18 & 36 \\
\cline { 2 - 4 } & Particular & 12 & 9 \\
\hline Tempo que leciona a \\
Disciplina?
\end{tabular}

Fonte: elaboração própria

Percebe-se que do total de 33 docentes participantes da pesquisa, 26 são do sexo feminino e 7 do sexo masculino. Os professores apresentam idades de 23 a 59 anos. Nota-se ainda que 18 professores se formaram em instituições públicas, 12 se formaram em instituições particulares e ainda dos 33 participantes da pesquisa, 3 deles tiveram a oportunidade de ingressar tanto em uma instituição pública como em uma particular.

O tempo médio em que os professores lecionam a disciplina de ciências varia de 4 meses a 25 anos e a carga horária dos discentes entrevistados varia de 16 a 52 horas semanais.

O quadro 3 apresenta em mais detalhes a formação dos docentes.

Quadro 3: Formação dos docentes

\begin{tabular}{|c|c|c|c|c|}
\hline Professores & EF 1 & EF 2 & EM & Formação \\
\hline P1 & $\mathbf{X}$ & & & Pedagogia \\
\hline P2 & $\mathbf{X}$ & & & Pedagogia e Graduação em Letras Português e Inglês. \\
\hline P3 & $\mathbf{X}$ & & & Pedagogia e História. \\
\hline $\mathrm{P} 4$ & & $\mathbf{X}$ & & Licenciatura e Bacharel em Ciências Biológicas. \\
\hline P5 & $\mathbf{X}$ & & & Agronomia e Ciências Agronômicas. \\
\hline P6 & $\mathbf{X}$ & & & Licenciatura em Biologia. \\
\hline P7 & $\mathbf{X}$ & $\mathbf{X}$ & $\mathbf{X}$ & Licenciatura em Matemática. \\
\hline P8 & & & $\mathbf{X}$ & Pedagogia e Licenciatura e Bacharel em Ciências Biológicas. \\
\hline P9 & & & $\mathbf{X}$ & Mestre em Matemática e Licenciatura Plena em Matemática. \\
\hline $\mathrm{P} 10$ & $\mathbf{X}$ & $\mathbf{X}$ & & Matemática e Química. \\
\hline P11 & & $\mathbf{X}$ & $\mathbf{X}$ & $\begin{array}{l}\text { Licenciado em Biologia e Química; especialista em ensino de } \\
\text { Química; especialista em gestão em Saúde Pública; Mestrando em } \\
\text { Física. }\end{array}$ \\
\hline P12 & $\mathbf{X}$ & & & Pedagogia. \\
\hline P13 & $\mathbf{X}$ & & & Pedagogia. \\
\hline P14 & $\mathbf{X}$ & & & Pedagogia e Psicopedagogia. \\
\hline P15 & $\mathbf{X}$ & & & Pedagogia \\
\hline
\end{tabular}




\begin{tabular}{|c|c|c|c|c|}
\hline Professores & EF 1 & EF 2 & EM & Formação \\
\hline P16 & $\mathbf{X}$ & & & Licenciado em pedagogia e Pós graduado em psicopedagogia. \\
\hline P17 & $\mathbf{X}$ & & & $\begin{array}{l}\begin{array}{l}\text { Graduado em pedagogia e Pós-graduação em Orientação supervisão } \\
\text { e gestão escolar. }\end{array} \\
\end{array}$ \\
\hline P18 & $\mathbf{X}$ & & & Pedagogia e Pós-graduação em Letramento e Alfabetização. \\
\hline P19 & $\mathbf{X}$ & & & $\begin{array}{c}\text { Pedagogia e pós graduado em Orientação Educacional e } \\
\text { Psicopedagogia. }\end{array}$ \\
\hline P20 & $\mathbf{X}$ & & & $\begin{array}{l}\begin{array}{l}\text { Licenciatura em pedagogia e Pós graduada em Orientação e } \\
\text { supervisão. }\end{array} \\
\end{array}$ \\
\hline P21 & $\mathbf{X}$ & & & $\begin{array}{c}\text { Licenciatura em pedagogia e Pós graduado em Gestão escolar: } \\
\text { Orientação e Supervisão. }\end{array}$ \\
\hline $\mathrm{P} 22$ & $\mathbf{x}$ & & & Licenciatura em Pedagogia e Pós graduado em Gestão escolar. \\
\hline P23 & & $\mathbf{X}$ & $\mathbf{X}$ & $\begin{array}{l}\text { Licenciado em Biologia; Mestre em genética e Melhoramento de } \\
\text { Plantas; Doutor em Produção Vegetal. }\end{array}$ \\
\hline $\mathrm{P} 24$ & & & $\mathbf{X}$ & Mestrado Completo \\
\hline P25 & & $\mathbf{X}$ & $\mathbf{X}$ & Licenciatura em Ciências Agrícolas e Ciências Biológicas. \\
\hline P26 & $\mathbf{X}$ & & & Pedagogia \\
\hline P27 & $\mathbf{X}$ & & & Pedagogia \\
\hline P28 & $\mathbf{X}$ & & & Pedagogia \\
\hline P29 & $\mathbf{X}$ & & & Psicologia \\
\hline P30 & $\mathbf{x}$ & & & Formação de Professores \\
\hline P31 & $\mathbf{X}$ & & & Pedagogia \\
\hline P32 & & $\mathbf{X}$ & & $\begin{array}{l}\text { Licenciatura em Biologia; Licenciatura em Letras Inglês; Mestrado e } \\
\text { Doutorado em Engenharia e Ciências dos Materiais. }\end{array}$ \\
\hline P33 & $\mathbf{X}$ & & & Formação de Professores. \\
\hline
\end{tabular}

Fonte: elaboração própria

Ao analisar o quadro 3, constata-se que dos 33 professores questionados 25 deles atuam no primeiro segmento do ensino fundamental, 7 no segundo segmento do ensino fundamental e 7 no ensino médio. Sendo que 5 destes professores atuando em mais de uma etapa da educação. Em relação à formação, é visível que grande parte dos professores não são formados na área da ciência. Destes professores, 19 são formados em pedagogia, isso é natural, pois é o requisito para atuar no primeiro segmento do ensino fundamental. Existem professores que são formados nas diversas licenciaturas como a de matemática (3 professores), letras (2 professores), história (1 professor). Há ainda aqueles formados em psicologia (1 professor), mestrado ( 1 professor). Tem aqueles formados a nível médio, sendo 2 professores. As formações mais voltadas para a ciência são: ciências biológicas (2 professores), agronomia e ciências agronômicas (1 professor), licenciatura em química (1 professor) e licenciatura de biologia (4 professores).

Finalizada a etapa de perfil do professor, a segunda etapa do questionário corresponde o que a instituição de ensino oferece aos professores, para que os mesmos tenham condições de elaborarem aulas mais diversificadas, com montagem de experimentos e outras atividades para o aprimoramento do conhecimento científico do educando, conforme apresenta o quadro 4. 
Quadro 4: Instituição de ensino e o ensino de ciências

\begin{tabular}{|c|c|c|}
\hline Instituição & N & \% \\
\hline \multirow{2}{*}{$\begin{array}{c}\text { Sua escola possui um espaço destinado às aulas de ciências, } \\
\text { como laboratórios? }\end{array}$} & Sim 8 & 24 \\
\cline { 2 - 3 } Sua escola possui equipamentos para o ensino de ciências? & Sim 9 & 27 \\
\cline { 2 - 3 } Sua escola elabora feira de ciências? & Não 24 & 73 \\
\hline Sim 21 & 64 \\
\cline { 2 - 3 } Sua escola desenvolve algum projeto de ciências? & Não 12 & 36 \\
\cline { 2 - 3 } & Sim 18 & 55 \\
\hline
\end{tabular}

Fonte: elaboração própria

A partir do quadro 4 nota- se que $76 \%$ das escolas não possuem um espaço destinado ao ensino de ciências, como um laboratório e que apenas $27 \%$ das escolas possuem algum equipamento para 0 ensino. Observa-se também que mesmo com todas essas dificuldades, algumas instituições buscam compor o seu ensino, como prova disso vemos que 64\% elaboram feiras de ciências. O desenvolvimento de projetos, como os de Feira de Ciências, é uma das estratégias descritas pelas Orientações Curriculares para o Ensino Médio (BRASIL, 2006) para estabelecer parcerias entre o professor e os alunos e dos alunos entre si, sendo o grande desafio do professor possibilitar ao aluno desenvolver as habilidades necessárias para a compreensão do papel do homem na natureza.

Além disso, 55\% dos professores vêem a necessidade de mudanças em suas aulas.

As questões abertas, nos quais os professores responderam em relação ao desenvolvimento de suas aulas, foram analisadas mediante a Análise Textual Discursiva (ATD). (MORAES; GALIAZZI, 2007). A ATD se estrutura a partir de três etapas, que compõem um processo cíclico:

a) Desmontagem dos textos ou unitarização: segundo Moraes e Galiazzi esta primeira etapa "implica examinar os textos em seus detalhes, fragmentando-os no sentido de atingir unidades constituintes, enunciados referentes aos fenômenos estudados." (MORAES; GALIAZZI, 207, p. 11), tendo o cuidado de se manter o contexto de onde o fragmento foi retirado. Nesta etapa deve-se dar atenção aos detalhes e nas partes dos componentes dos textos, uma fase de decomposição necessária a toda análise. É o próprio pesquisador quem decide em que medida fragmentará seus textos. Dessa desconstrução dos textos surgem as unidades de análise, também chamadas de unidades de significado ou sentido. (MORAES; GALIAZZI, 2007, p. 18). Essas unidades podem ser empíricas, coletadas para a pesquisa, e teóricas, provenientes dos autores utilizados para embasar o tema pesquisado. Cada unidade de análise deve receber título, que represente a ideia principal da unidade e código, a fim de identificar seu texto de origem, bem como sua localização dentro desse texto.

b) Estabelecimento de relações ou categorização: consiste na construção de relações entre as unidades de análise, tanto as empíricas, quanto as teóricas. Fazemos isso num processo recursivo de leitura e comparação entre as mesmas, resultando em conjuntos que apresentam elementos semelhantes, daí surgem às categorias. Segundo Moraes e Galiazzi (2007), o processo de categorização na ATD é longo e exige do pesquisador uma impregnação aprofundada nas informações e, ao mesmo tempo, a eliminação do excesso de informações, apresentando o fenômeno de modo sintético e ordenado. Podemos 
afirmar que a categorização é um processo de criação, ordenamento, organização e síntese. Constitui, ao mesmo tempo, processo de construção de compreensão de fenômenos investigados, aliada à comunicação dessa compreensão por meio de uma estrutura de categorias. (MORAES; GALIAZZI, 2007, p. 78). Importante ressaltar que diante das múltiplas leituras de um texto, uma mesma unidade pode ser lida de diferentes perspectivas, resultando em diferentes sentidos, sendo aceito dessa forma que uma mesma unidade possa ser aceita em mais de uma categoria. Os autores afirmam que "isso representa um movimento positivo no sentido da superação da fragmentação." (MORAES; GALIAZZI, 2007, p. 27). Outra característica referente à categorização reside no fato da ATD aceitar tanto o estabelecimento de categorias a priori quanto de categorias emergentes ou ainda, categorias mistas (a priori e emergentes). Neste trabalho as categorias foram emergentes.

c) Comunicação ou produção de metatextos: nessa etapa, percebe-se uma nova compreensão do todo, possibilitada pelo intenso envolvimento nas etapas anteriores. O objetivo agora será elaborar um texto descritivo e interpretativo, o qual denomina-se metatexto, a partir das categorias. Segundo Moraes e Galliazzi (2007) saber empregar as categorias construídas na análise para organizar a produção escrita é uma forma de atingir descrições e interpretações válidas dos fenômenos investigados. Afirmam ainda que "a qualidade dos textos resultantes das análises não depende apenas de sua validade e confiabilidade, mas é, também, consequência do fato de o pesquisador assumir-se autor de seus argumentos." (MORAES; GALIAZZI, 2007, p. 32). Desse modo, a ATD pode ser compreendida "como um processo auto-organizado de construção de novos significados em relação a determinado objetos de estudo, a partir de materiais textuais referentes a esses fenômenos." (MORAES; GALIAZZI, 2007, p. 45).

\section{RESULTADOS}

Com base na ATD, a análise das respostas dos professores acerca de sua prática em sala de aula será comunicada através de metatextos. A partir da análise foi construído um metatexto a partir de uma categoria emergente: o ensino de ciências que tem sido praticado no município de Cambuci/RJ.

Quando perguntados sobre como planejam suas aulas, os docentes apontam um conjunto de critérios utilizados para organizar a mesma. Nota-se que parte dos professores utilizam como estratégia pesquisas baseadas em livros didáticos e em plataformas online, como afirma o professor P29: "Buscando informações nos livros e pesquisando na internet sobre o tema proposto", retratando dessa forma uma estratégia de planejamento semelhante com a de Guimarães, Echeverría e Moraes: "Não podemos deixar de considerar a importância do livro didático, principalmente para alunos que têm acesso restrito a materiais e recursos que disponibilizam informações ou imagens de outros contextos e realidades.” (GUIMARÃES; ECHEVERRÍA; MORAES, 2006, p. 311). Entretanto, os mesmos autores argumentam que a utilização do livro didático: “[...] sua utilização, sem tempo para análise e reflexão pouco contribui para a problematização da prática pedagógica e, consequentemente, para mudanças de concepções em relação aos conteúdos escolares.” (GUIMARÃES; ECHEVERRÍA; MORAES, 2006, p. 311).

Outro professor ao se referir a sua forma de planejamento diz "Baseado no currículo mínimo (P9) essa mesma afirmação é repetida por vários professores, dos 33 professores, 17 afirmaram que planejam suas aulas com base no currículo mínimo, eao analisar essas afirmações, é visível que os docentes apresentam um caráter conteudista. Tendo em vista as afirmações dos professores, percebe-se que o modelo didático trabalhado é o tradicional que "focaliza o conteúdo, e se caracteriza pela ênfase na transmissão destes do professor para o aluno.” (HYGINO; MOURA; LINHARES, 2014, p. 45). "Porlán (1998, p. 65) considera que, na perspectiva de um modelo didático tradicional, os conteúdos 
são considerados como uma 'simplificação do conhecimento científico'." (GUIMARÃES; ECHEVERRÍA; MORAES, 2006, p. 312). De todos os professores questionados, apenas o professor P15 relata que "Baseando-me nos espaços escolares".

Tendo em vista os critérios abordados por cada professor, nota- se que apenas um, o P15, preocupa-se em relacionar seu ensino ao que escola que atua possui para oferecer aos alunos. Para fechar esses critérios, os docentes ainda se baseiam no cotidiano do aluno, como diz o professor P21: "Realidade e vivência do aluno". Tendo ainda um professor, o $\mathrm{P} 21$, que trabalha com o modelo didático espontâneo, no qual a "[...] realidade dos alunos é levada em consideração em todas as atividades”. (HYGINO; MOURA; LINHARES, 2014, p. 45). É possível perceber que ao planejarem suas aulas os professores não objetivam a formação cidadã e consciente de seus alunos, assim como mostra do modelo investigativo de ensino.

Ao questionar os professores sobre o que desejam alcançar em suas aulas, os mesmos apresentam diversos objetivos esperados. Constata-se que grande parte dos docentes possuí um enfoque maior no aprendizado do aluno, como afirma o professor P13 "Que os alunos alcancem o aprendizado de maneira significativa”. Em contrapartida, segundo os autores Pozo e Crespo: "Aprender ciência deve ser, portanto, um exercício de comparar e diferenciar modelos, não de adquirir saberes absolutos e verdadeiros.” (POZO; CRESPO, 2009, p. 21).

Outros professores procuram alcançar em suas aulas uma maior dinamicidade, trabalhando com ludicidade, despertando a curiosidade e atraindo os alunos, como afirmam os professores P01, P21 e P24, "Que os alunos aprendam de maneira lúdica" (P1), "Despertar a curiosidade dos alunos e leválos a conhecer mais o seu corpo e o mundo a sua volta" (P21), "Primeiramente o interesse do aluno, depois tento somar as deficiências de cada aluno" (P24). Tendo ainda, aqueles professores que prezam por contribuir para a formação acadêmica e crescimento lógico de seus alunos, como afirmam os professores P09 e P14, "Propiciar ao aluno situações onde ele possa desenvolver o raciocínio e o sendo crítico" (P9), "Que meus alunos cresçam enquanto alunos e sejam cidadãos ativos $e$ reflexivos" (P14). Ao observar as afirmações, conclui-se que a metodologia utilizada baseia-se no modelo tecnológico que diz: "A avaliação tem como objetivo quantificar a aprendizagem e verificar a eficiência desta sistemática de ensino. Neste modelo o aluno também tem uma participação passiva, devendo participar das atividades programadas.” (HYGINO; MOURA; LINHARES, 2014, p. 45). E a partir das afirmações de alguns professores como o P09 e o P14, conclui-se que o modelo didático trabalhado por eles é o modelo investigativo, no qual: "Enfatizam-se as situações problemas que exigem dos alunos posturas investigativas, nas quais, devem elaborar hipóteses e propor soluções.” (HYGINO; MOURA; LINHARES, 2014, p. 45).

Com a pergunta referente às estratégias de ensino utilizadas pelo professor em sala de aula, primeiramente verifica-se a confusão entre recursos e estratégias. De acordo com Garcia e Porlán (2000), esta confusão é um obstáculo a ser superado na formação do professor, pois caracteriza uma concepção estática e linear dos processos de ensino.

Os docentes assinalam que dispõem de meios e formas dinâmicas, utilizando de diversos recursos como afirma o professor P 08 "Pesquisas, aulas expositivas, recursos tecnológicos” e o professor P03: "Data show, experiências e pesquisas”. Há ainda aqueles professores que utilizam como estratégia o uso de experimentos como mencionado pelo professor P 09: "Procuro adequar teoria à prática com experimentos que é possível". Os demais professores questionados afirmam que suas estratégias se baseiam no diálogo, observação do cotidiano e aula expositiva, como dito pelos professores P29: "Diálogo em sala de aula sobre o tema”, P22: "Procuro trazer o conteúdo para a vida e experiências do educando" e P23: “Aulas expositivas com uso de testes”, respectivamente. Ao utilizarem todas essas estratégias já mencionadas, os docentes condizem com a afirmação de Duchsl que diz: "não apenas um produto acumulado em forma de teorias ou modelos, e é necessário levar para os alunos esse caráter dinâmico e perecedouro dos saberes científicos." (DUCHSL, 1994 apud POZO; CRESPO, 2009, p. 21). Tendo em vista as afirmações dos professores, conclui-se que: “[...] o 
modelo tecnológico é o mais evidente que procura inovar o modelo tradicional, incorporando ao currículo da escola atividades práticas, materiais didáticos atualizados e um rigoroso detalhamento dos planejamentos de ensino.” (HYGINO; MOURA; LINHARES, 2014, p. 45).

Entretanto, percebe-se que as ideias prévias dos estudantes não consideradas na resposta de nenhum dos professores, como uma estratégia em sala de aula. De acordo com Harres (1999), a desconsideração dos conhecimentos que os alunos trazem é coerente com uma postura epistemológica na qual a ciência leva a verdades definitivas e incontestáveis. Além disso, o uso de problemas no ensino de ciências, relacionados também a questões sociais, políticas, econômicas e ambientais, assim como mostra Sasseron (2015), como fundamental para o ensino de ciências sequer foi mencionado pelos professores. Todos estes fatores não revelados pelos professores demonstram um distanciamento de um modelo de ensino investigativo.

Ao serem questionados sobre a forma como os professores avaliam seus alunos, percebe-se que a grande maioria dos docentes utiliza como critério avaliativo a participação, como afirma o professor P19: "Participação e relato em aula". A interação por parte dos alunos também é de extrema importância na hora do professor compor seu sistema avaliativo, como dito pelo P02: "Por meio do relacionamento interpessoal”. Tendo em vista estas afirmações, percebe-se que o modelo didático utilizado por estes professores é o modelo espontâneo, onde "a ênfase está nas ideias e interesses dos alunos.” (HYGINO; MOURA; LINHARES, 2014, p. 45). Entretanto, as avaliações propriamente ditas também são elaboradas de modo que os mesmos mostrem de forma escrita o que lhes foi ensinado em sala de aula, isso é afirmado pelo professor P01: “Avaliações diagnósticas”. Segundo Pozo e Crespo "A ideia básica do chamado enfoque construtivista é que aprender e ensinar, longe de serem meros processos de repetição e acumulação de conhecimentos, implicam transformar a mente de quem aprende, que deve reconstruir em nível pessoal os produtos e processos culturais com o fim de se apropriar deles.” (POZO; CRESPO, 2009, p. 20). Diante disso, percebe-se que os professores também compartilham de formas de avaliação com características de um modelo tradicional.

Os professores motivam seus alunos em aprender ciências com diversos recursos como: "Através de aula com atividades práticas e aulas audiovisuais" e "Com aulas diferenciadas, lúdicas" como afirmado pelos professores P04 e P26, respectivamente. A motivação também acontece através da utilização de experimentos como afirma o P15: "Levando-os a fazer experiências". A grande maioria dos professores questionados aponta que a estratégia mais eficaz para motivar seus alunos a aprenderem ciências é relacionar a disciplina com o cotidiano como afirma o professor P14: "Procurando mostrá-los que ciência é vida, faz parte do nosso cotidiano", sendo assim, o ensino de ciências "tem como função formativa essencial fazer com que os futuros cidadãos interiorizem, assimilem a cultura em que vivem, em um sentido amplo, compartilhando as produções artísticas, científicas, técnicas, etc. próprias dessa cultura e compreendendo seu sentido histórico.” (POZO; CRESPO, 2009, p. 23).

A criatividade também é um recurso utilizado pelos professores, segundo o P06: "Atividades dinâmicas, receitas saudáveis”, outros professores motivam seus alunos por meio de outros recursos como o apresentado pelo professor P07: "Usando fatos que contrariam e senso comum"e apresentado pelo professor P18: "Busco despertar curiosidade sobre o assunto". Nota-se que de todos os 33 professores questionados apenas 1 deles utiliza a interdisciplinaridade como forma de motivação para fazer com que os alunos queiram aprender ciências, como dito pelo professor P02: “Abordando-a nas leituras informativas, literárias e produções textuais”. Com base em todas as afirmações contidas acima, percebe-se que existem uma mescla entre dois modelos didáticos, o modelo tecnológico, o qual procura inovar o modelo tradicional, incorporando ao currículo da escola atividades práticas, materiais didáticos atualizados e um rigoroso detalhamento dos planejamentos de ensino e o modelo espontâneo, o qual enfatiza as ideias e interesses dos alunos. (HYGINO; MOURA; LINHARES, 2014). 


\section{CONSIDERAÇÕES FINAIS}

Esta pesquisa buscou fazer um diagnóstico compreender como é o ensino de ciências praticado no município de Cambuci/RJ. Deste modo, buscou identificar os recursos disponíveis nas escolas para este ensino e como são as aulas de ciências. A partir destes dados, pode ser possível traçar como é o cenário do ensino de ciências atualmente neste município e quais aspectos apresentam mais necessidades de mudanças.

O município de Cambuci/RJ conta com 6 distritos. Na tentativa de mapear todos os distritos, foi selecionada uma escola em cada distrito. Entretanto, em dois distritos, foi necessário realizar a pesquisa em 2 escolas, a fim de mapear o primeiro e segundo segmento do ensino fundamental e ensino médio. Para isso, foram selecionadas 8 escolas do município. Nestas escolas, foram pesquisados 33 professores, os quais responderam a um questionário elaborado pelos pesquisadores.

A partir das análises do questionário, foi possível traçar o perfil dos professores, os recursos disponíveis nas escolas para o ensino de ciências e como o ensino é praticado em sala de aula.

Com a análise do perfil dos professores, pode-se perceber que os professores apresentam formações diversas, sendo poucos formados na área de ciências especificamente. Muitos atuam em diferentes segmentos do ensino e alguns possuem carga horária bastante elevada.

A partir da análise dos recursos escolares, percebeu-se que as escolas não possuem espaços específicos destinados ao ensino de ciências, entretanto, alguns professores trabalham com experimentos e outros conseguem elaborar feira de ciências em suas escolas.

No que se refere à prática de sala de aula, as respostas dos professores foram analisadas mediante a ATD e buscou-se identificar o modelo didático predominante entre os docentes.

A partir da análise pode-se perceber que existe um predomínio do modelo tradicional, aquele mais ligado a transmissão de conteúdos e provas com memorização de conteúdos. Também predomina o modelo tecnológico, no qual busca diferentes atividades para o seu ensino, como o uso de experimentos. E em alguns casos também foi identificado o modelo didático espontaneista, no qual a participação dos alunos é considerada. Dessa forma, assim como identificado por Guimarães, Echeverría e Moraes (2006), a análise dos dados desta pesquisa, mostra a presença de divergentes orientações didáticas resultante de diferentes concepções de educação escolar. Diante disso, não existe um modelo didático predominante que se enquadre nos modelos identificados pela literatura, entre os professores de ciências investigados.

Com este levantamento do ensino de ciências no município de Cambuci/RJ pode perceber que o uso de experimentos é bem explorado pelos professores, entretanto, como não existe espaços específicos, talvez estes possam ser elaborados com materiais de baixo custo. Além disso, a realização de feira de ciências também é bastante presente em muitas escolas do município que poderia ser expandido para outras escolas.

Além disso, pode-se diagnosticar a necessidade de mais vínculo com questões relacionadas a ciência, a tecnologia, a sociedade e ao meio ambiente, na tentativa de oferecer aos alunos uma formação mais crítica e cidadã.

\section{REFEREENCIAS}

AULER, D.; DELIZOICOV, D. Alfabetização científico-tecnológica para quê? Rev. Ensaio, Belo Horizonte, v. 3, n. 2, p.122-134, jul./dez. 2001.

BRASIL. Secretaria de Educação Básica. Ministério da Educação e Cultura. Parâmetros Curriculares Nacionais (PCN). Brasília: MEC/SEF, 1997. 
BRASIL. Secretaria de Educação Básica. Ministério da Educação e Cultura. Programa Nacional de Apoio às Feiras de Ciências da Educação Básica: Fenaceb. Brasília: MEC/SEB, 2006.

CHASSOT, A. A educação no ensino de Química. Ijuí: Unijuí, 1990.

CHASSOT, A. Alfabetização científica: questões e desafios para a educação. Ijuí: UNIJUI, 2000.

CHROBAK, R.; BENEGAS, M. L. Mapas conceptuales y modelos didacticos de profesores de química. In.: CAÑAS, A. J.; NOVAK, J. D. (ed.). Concept maps: theory, methodology, technology: proceedings of the second international conference on concept mapping. San José: CMC, 2006. Disponível em: http://cmc.ihmc.us/cmc2006Papers/cmc2006-p215.pdf. Acesso em: 24 out. 2016.

DELIZOICOV, D.; ANGOTTI, J. A.; PERNAMBUCO, M. M. Ensino de Ciências: fundamentos e métodos. São Paulo: Cortez, 2009.

FOUREZ, G. Crise no Ensino de Ciências? Investigações em Ensino de Ciências, Porto Alegre, v. 8, n. 2, p. 109-123, maio/ago. 2003. Disponível em: https://www.if.ufrgs.br/cref/ojs/index.php/ienci/article/view/542/337. Acesso em: 09 fev. 2019.

GARCÍA, J. E.; PORLÁN, R. Ensino de ciências e prática docente: uma teoria do conhecimento profissional. Caderno Pedagógico, Lajeado, s/v, n. 3, p. 7-42, 2000. Disponível em: http://www.univates.br/files/files/univates_novo/editora/arquivos_pdf/caderno_pedagogico/caderno_p edagogico3/Ensinodecienciasepraticadocente.pdf. Acesso em: 09 fev. 2019.

GARCÍA PÉREZ, F. F. Los modelos didácticos como instrumento de análisis y de intervención em La realidad educativa. Biblio3W: revista bibliográfica de geografía y ciencias sociales, Barcelona, s/v, n. 207, feb. 2000. Disponível em: http://www.ub.edu/geocrit/b3w-207.htm . Acesso em: 24 out. 2016.

GIL, A. C. Métodos e técnicas de pesquisa social. São Paulo: Atlas, 1999.

GIL-PÉREZ, D.; CARVALHO, A. M. P. Formação de professores de ciências. São Paulo: Cortez, 1992.

GUIMARÃES, M. A G.; ECHEVERRÍA, A. R.; MORAES, I. J. Modelos didáticos no discurso de professores de ciências. Investigações em Ensino de Ciências, Porto Alegre, v. 11, n. 3, p. 303-322, set./dez. 2006.

HYGINO, C. B.; MOURA, S. A.; LINHARES, M. P. Modelos didáticos na formação inicial de professores de Física: uma apreciação na perspectiva da análise do discurso. Ciênc. educ., Bauru, v. 20, n. 1, p. 43-59, mar. 2014.

IBGE. Síntese de Indicadores Sociais. Uma análise das condições de vida da população brasileira 2015. Rio de Janeiro: IBGE, 2015. 134 p.

IBGE. Indicadores Sociais Municipais: uma análise dos resultados do universo do Censo Demográfico 2010. Rio de Janeiro: IBGE, 2010. 149 p.

MALAFAIA, G.; RODRIGUES, A. S. L. Uma reflexão sobre o ensino de ciências no nível fundamental da educação. Ciência \& Ensino, São Paulo, v. 2, n. 2, jun. 2008. Disponível em: http://www.cienciamao.usp.br/tudo/exibir.php?midia=rcen\&cod=_umareflexaosobreoensinod. Acesso em: 24 out. 2016.

MALDANER, O. A. Situações de estudo no ensino médio: nova compreensão de educação básica. In.: NARDI, R. (org.). A pesquisa em ensino de Ciências no Brasil: alguns recortes. São Paulo: Escrituras, 2007. p. 239-253.

MORAES, R.; GALIAZZI, M. do C. Análise textual discursiva. Ijuí: Unijuí, 2007. 
PORLÁN ARIZA, R.; RIVERO GARCÍA, A.; MARTÍN DEL POZO, R. Conocimiento profesional y epistemología de lós profesores I: teoría, métodos e instrumentos. Enseñanza de las Ciencias, Barcelona, v. 15, n. 2, p. 155-171, maio/ago. 1997. Disponível em: https://www.raco.cat/index.php/Ensenanza/article/view/21488/93522. Acesso em: 24 out. 2016.

PORLÁN ARIZA, R.; RIVERO GARCÍA, A.; MARTÍN DEL POZO, R. Conocimiento profesional y epistemología de lós profesores II: estudios empíricos y conclusiones. Enseñanza de las Ciencias, Barcelona, v. 16, n. 2, p. 271-288, maio/ago. 1998. Disponível em: https://www.raco.cat/index.php/Ensenanza/article/view/21534. Acesso em: 24 out. 2016.

POZO, J. I. ; CRESPO, M. G. À. A aprendizagem e o ensino de Ciências: do conhecimento cotidiano ao conhecimento científico. São Paulo: Artmed, 2009.

SASSERON, L. H. Alfabetização científica, ensino por investigação e argumentação: relações entre ciências da natureza e escola. Revista Ensaio, Belo Horizonte, v. 17, n. especial, p. 49-67, nov. 2015. Disponível em: http://www.scielo.br/pdf/epec/v17nspe/1983-2117-epec-17-0s-00049.pdf. Acesso em: 24 out. 2016.

TARDIFF, M. Saberes docentes e formação profissional. Petrópolis: Vozes, 2002. 